\title{
Firma y autoría en Budapeste, de Chico Buarque, y en Divórcio, de Ricardo Lísias
}

Cristian Molina ${ }^{1}$

\section{Budapeste, de Chico Buarque}

En marzo de 2013, se desató una polémica por el Proyecto de Ley no 393/2011 sobre biografías no autorizadas, que iba a ser sancionado en Brasil con el objeto de liberar a los biógrafos de consecuencias y persecuciones legales ligadas a su trabajo. Fue en el plano de los periódicos brasileños donde se produjeron enfrentamientos que involucraron a diferentes artistas, escritores, medios y académicos. La irrupción de un grupo formado, entre otros, por Caetano Veloso, Roberto Carlos y Chico Buarque, llamado "Procure Saber", agitó el descontento, al punto de que en una columna de $O$ Globo titulada "Penso eu", Buarque irrumpió con virulencia y ofuscado ante lo que consideraba un avasallamiento:

Pensei que o Roberto Carlos tivesse o direito de preservar sua vida pessoal. Parece que não. Também me disseram que sua biografia é a sincera homenagem de um fã. Lamento pelo autor, que diz ter empenhado 15 anos de sua vida em pesquisas e entrevistas com não sei quantas pessoas, inclusive eu. Só que ele nunca me entrevistou (Buarque, 2013, p. 1).

Esa reacción termina con una advertencia a $O$ Globo: si sus composiciones son interpretadas al aire por la señal televisiva del multimedios, en un supuesto homenaje, llamativo porque se daría en el canal que en los años 1970 se encargó de censurar su firma, él mismo intervendría legalmente y se convertirá en el censor de la transmisión. El enojo de Buarque y la posición autoral de revenge autoritaria - se esgrime como censor del devenir de sus composiciones - en la que inscribe su firma, me parecieron, al principio, una inflexión evidente con la imagen de autor literario que desde la ficción, sobre todo con la publicación de Budapeste (2003), Buarque reafirmaba.

\footnotetext{
${ }^{1}$ Doctor en humanidades y artes y profesor de la Universidad Nacional de Rosario, Rosario, Santa Fe, Argentina. Es investigador asistente de Conicet. E-mail: molacris@yahoo.com.ar
} 
Casi una aparente disonancia con el avatar de las firmas y las duplicaciones que, no inocentemente, involucraban en la ficción a un ghost writer que escribía biografías por encargo: José Costa. Lo que comencé a preguntarme es ¿había mutado algo o no, desde la publicación de Budapeste en 2003 con esta irrupción de la firma Chico Buarque en un periódico de 2013, bajo el don de "cantor, compositor y escritor" en que la columna inscribía su firma, reafirmando una imagen autoral anfibia (músico / escritor)?

Budapeste irrumpió en la escena brasileña en el año 2003, publicado por Companhia das Letras. A primera vista, la tapa y la contratapa del libro espejan dos firmas enfrentadas: la de Chico Buarque y la de José Costa. Es decir, anverso y reverso del libro se tocan a partir de las firmas; algo que podría unir o enfrentarlas. Si analizamos el libro, y la inscripción de la historia del ghost writer, ambas posibilidades se presentan como factibles de ser leídas, y aunque parezca contradictorio, no lo es. Porque si José Costa es desconocido, una firma oculta sin valor hasta el final de la novela, que escribe literatura en una lengua ajena y solo en los momentos que le quedan libres de su actividad laboral en la agencia y en la institución literaria húngara, a partir de un verdadero proceso de aprendizaje que va de la escritura por encargo al contacto con una lengua poética extranjera; Chico Buarque, por el contrario, según Florencia Garramuño es "uno de los músicos más importantes de ese movimiento, que durante las décadas de 1960 y 1970 tomó las raíces del samba aggiornadas por la bossa nova para provocar el estallido de eclecticismo rítmico y melódico que se definió con las equívocas siglas de MPB (Música Popular Brasileira). Sin embargo, lo cierto es que sus obras de teatro, novelas y participaciones en cine resultan piezas tan bien acabadas - y en algunos casos, tan conocidas - como sus mismas canciones" (Garramuño, 2015, p. 55).

Es decir, mientras José Costa es un desconocido, Chico Buarque es una firma potente en la cultura brasileña que compone una obra "que se desliza con sorprendente facilidad desde la música popular hacia la literatura, el cine y el teatro". Ahora bien, si Chico Buarque es, en 2015, una potente firma cultural que involucra y ejecuta diferentes artes, desbaratando los límites entre ellas, por lo menos desde la década de 1960, lo cierto es que su don de escritor no siempre fue reconocido como tal. Según Georgiana Coelho Santos (2012), Chico Buarque fue para la mayoría de la crítica especializada, antes de la publicación de Budapeste, un dudoso escritor por ser un artista masivo. Fue a partir de Budapeste y a 
través de una operación crítica y de prensa en la que estuvo involucrado hasta José Saramago, que la identidad de escritor de Chico Buarque se consolidó. Es más, Buarque mismo llega a considerar que Budapeste es su primer libro. Por ende, la condición contradictoria y de desconocimiento de parte de la crítica y de la academia como escritor para Chico Buarque es análoga a la condición anónima y al pasaje del ghostwriter al escritor reconocido. Situación con la cual el libro juega en su diseño gráfico.

Estos espejamientos se refuerzan con la película Budapeste (2009), bajo la dirección de Walter Carvalho. Aunque la relación entre libro y película podría considerarse un tradicional caso de trasposición cinematográfica, es evidente que se trata de una operación artística más amplia que extiende y profundiza entre formatos una misma ficción y un mismo gesto. Si la tapa y la contratapa del libro espejan el nombre de Chico Buarque con el de José Costa, por un lado, y si el final del libro y de la película ponen en evidencia una mise en abyme de la ficción, tanto en un caso como en el otro, lo que se complejiza es una firma y su atribución autoral. Pero es, además, lo que explica dos mutaciones de la película que es necesario enfatizar: por un lado, el recurso de la estatua al "escritor desconocido" en Hungría, el énfasis en los extensos momentos de intensidad líricas de las imágenes fílmicas entre José y el monumento que en el libro son inexistentes, enfatizando el desconocimiento del escritor como uno de los centros de la ficción. Por el otro, la aparición fugaz de Chico Buarque en un cameo sobre el final de la película, donde él mismo actúa en la ficción cinematográfica de groupie desconocido de José Costa cuando ha obtenido su reconocimiento. Es decir, tanto película como libro, a partir de sucesivas mutaciones tienden a enfatizar, el no reconocimiento como escritor de la firma Chico Buarque, al tiempo que su enorme potencia cultural.

Algo que esta ficción expandida refuerza cuando, en el libro, llegamos al final y sabemos que quien firma lo que leímos es José Costa y cuando, en la película, el plano se abre a un fuera de campo ilusorio y enfoca la cámara del director que filma la película, pero cuyo lugar está vacío. Apenas se oye su voz, fantasmática, que ordena: “- ¡Corten!”. De modo que si el libro pone en una zona de indeterminación ficcional la atribución autoral a partir de un espejo entre las firmas, la película pone en escena y tensiona al autor del libro en un cameo con un director ausente en el cuadro de la cámara filmadora, generando una zona anfibia donde no solo literatura y cine se tocan, sino, donde, por eso mismo, la atribución autoral de la ficción queda suspendida en una duplicación de firmas que las atraviesa. 
Porque en la película, ¿qué firma autoral es la más potente? Lo primero que tenemos que advertir es que en el cine, la música y la televisión, la relación entre firma y autoría tiene un carácter muy diferente, o por lo menos más complejo del que presupone la literatura. Mientras las primeras artes tienden a apoyarse en relaciones indirectas entre firma y autoría, en la literatura y en la pintura (clásica), generalmente, hay una relación más directa entre firma y autoría. Esto se explica porque las firmas de una película no incluyen solo la del director, que es generalmente el que se asimila con la firma y función autor, aunque no necesariamente con los derechos de propiedad que suelen pertenecer al productor, sino que involucran, además, las firmas de las estrellas que dotan al mismo de un valor singular tanto como la firma de la dirección (Jullier y Leveratto, 2012; Gardies, 2014). En el caso de la música, las relaciones entre compositor, intérprete y a veces banda, también implica diferentes articulaciones no tan directas entre firma y autoría (tanto función autor como derechos de autor). Es decir, mientras estas artes tienden a presentar relaciones entre firma y autorías colectivas, en cambio, en la literatura y la pintura, esas relaciones son más directas, si bien también intervienen las firmas editoriales en la atribución de derechos de autor y si bien la asociación entre autor, sujeto, firma e imagen, como señala Marcelo Topuzian (2014), siempre dan lugar a un resto inasible. ${ }^{2}$ Con esto quiero decir que si en el caso de la película de Buarque, la presencia de éste como actor en la misma viene a signar la ficción atribuida a Carvalho, al mismo tiempo que a potenciar la versión literaria de la película. Ese cameo sobre el final del filme interviene potenciando la firma de Carvalho, al tiempo que potencia la obra literaria y la firma artística de Buarque - icónica en la música brasileña. Lo que se observa es cómo una ficción literaria, mediante este sistema de firmas y atribuciones autorales en la cultura contemporánea propende a generar una expansión de los formatos a partir de una misma ficción autoral, que complejiza y pone en contacto diversas prácticas de la cultura contemporánea.

\footnotetext{
${ }^{2}$ En el caso de la pintura clásica, en el sentido más llano de este término, Arnold Hauser (1978) ha señalado cómo desde el Renacimiento la firma de artista se volvió central en la conformación de marcas autorales que dieron origen al protomercado de los bienes culturales. Este proceso implicó, al mismo tiempo, una potenciación social de las firmas mediante el mecenazgo de la obra firmada por un artista. En las prácticas del arte contemporáneo, las atribuciones autorales colectivas conviven con las clásicas. Algo que puede observarse en las complejas atribuciones autorales de obras en las que la producción de la misma involucra a los espectadores en un entramado relacional como el que plantea Nicolas Bourriaud en Estética relacional (2008), entre otro casos.
} 
Y acá volvemos a la pregunta que nos hacíamos al inicio de este trabajo. El que firma la polémica columna de 2013 no es solo el Chico Buarque, compositor o cantante, sino también el escritor, por el que, incluso, después de ganar el Premio Bravo de literatura en 2011, uno de los títulos periodísticos fue "Sim, Chico é um grande escritor". Solo que para que a la firma potente y siempre polémica de Buarque se le otorgue el don de escritor, compuso ficciones de escritor/autor en las cuales afantasmarse a partir de una duplicación en espejo tanto en el libro Budapeste como en la película de Carvalho, y de modo análogo en el éxito de su práctica musical, al punto de volverse un desconocido escritor en la película o una mera firma que en realidad solo marca la ficción de otro en el libro. Es decir, Buarque pasó por una deflación como escritor, incluso en un juego de duplicidades en la ficción autoral, donde quitaba la autoridad a la potente firma cultural Chico Buarque para cargarla, a partir de ello, de la potencia de escritor.

\section{Divórcio, de Ricardo Lísias}

Casi en las antípodas podría ubicarse la performance autoral de Ricardo Lísias en la novela Divórcio (2013a), publicada el mismo año de la polémica de Chico Buarque por la ley de las biografías no autorizadas. Soy consciente de la distancia temporal que separa a un escritor actual, aunque fuerte, con una firma cultural potente como la de Chico Buarque que se consolida desde los años 1960. Sin embargo, sospecho que ambos gestos de autoría que desprenden el uso de las firmas en ambos responden a una misma matriz a partir de la cual difieren no solo de sí mismas, sino de otras prácticas en la literatura brasileña contemporánea, pero con las que no dejan de tender a una relación de cercanía más que de distancia.

La novela, como sabemos, se sostiene en la coincidencia onomástica de Firma, narrador y personaje a partir de una primera persona que los enlaza. Pero hay múltiples procedimientos que generan interferencias y que rompen la atribución directa entre esas instancias y el sujeto Ricardo Lísias, incluso el autor de Divórcio, Ricardo Lísias. Por un lado, las contradictorias declaraciones de la narración respecto de sí misma, que a veces asegura que todo es ficción, mientras, otras, que todo es realidad. No pretendo leer estas zonas anfibias desde la clasificación cuasi genérica de la autoficción, algo que puede resultar problemático y que ha sido emprendido, creo, con un afán tranquilizador que la misma obra de Lísias 
trata de desplazar (Martins, 2014). Sino que quiero remarcar que en esa zona anfibia, la novela avanza suspendiendo la realidad y la ficción de lo narrado, y dejando al lector en una tensión irresuelta. Por ende, no pretendo, tampoco, pensar estas tensiones desde la idea del "falso mentiroso" (Martins, 2014), sino de una verdad de la novela que se complementa con declaraciones del propio Ricardo Lísias al respecto en algunas entrevistas: "não posso responder pois não acho possível que um texto de ficção contenha o autor em si" (Lísias en Martins, 2014, p. 43). Una ficción, plantea Lísias, no puede contener el autor en sí; de ahí que Divórcio no pueda leerse como mera autoficción y que la atribución autoral esté, por lo menos, suspendida, puesta en entredicho. ¿Pero cómo podemos leer esta declaración? La lectura que arriesgo es que la ficción de Divórcio, incluso aunque use en su composición restos de lo real - y la firma del narrador es uno de esos restos que coincide con la del autor y el sujeto Lísias -, es una ficción autoral que consiste en desaparecerlo detrás de la absoluta presencia de su firma como escritor. ${ }^{3}$

Esto se logra a partir de dos procedimientos más que son complementarios. Por un lado, una ficcionalización de la posición y visión del mundo resentida, machista y políticamente incorrecta que se desprende de la novela. No leo allí, tampoco, una corrosiva ironía, sino la composición de un pathos propio de una ficción ideológica. En este sentido, podemos comprender por qué Renata Magdaleno (2014) sitúa la novela dentro las posibles discusiones contemporáneas sobre el estatuto de la literatura y las críticas del presente, puesto que propende a crear realidad pero como ficción absoluta que se despliega, incluso, en el plano de las posiciones ante el mundo del narrador protagonista y de la firma Lísias. Por eso, no solo desaparece en su aparición el autor, sino que, incluso, la ficción tiende a degradarlo y a dejar tanto a este como a la confusión con su firma y con su autor en una zona patética e incorrecta desde el plano ético y político. Es en este sentido que el divórcio no es solo entre Lísias y su ex mujer, sino entre los Lísias que la ficción autoral presentifica y compone entre ese que escribe, pero que se ha declarado muerto, enfatizando el trauma que ha escindido al sujeto y que es

\footnotetext{
${ }^{3}$ En "El concepto de ficción" (1991) Juan José Saer definió la misma como una construcción o artificio formal que no se opone necesariamente ni a la realidad ni al concepto de verdad. En este sentido, si Lísias tiende a usar este concepto para desacreditar la correspondencia directa con la realidad y ponerlo como verdad de la escritura, también se comprende porqué en la novela y en sus propias declaraciones, por momentos, la relación - la articulación con la realidad - se plantean en simultáneo.
} 
correlativo de la escisión entre firma y autor. Y he allí la potencia de esa escritura. Se trata de la escisión entre ese Lísias incorrecto que asume la narración con el otro Lísias, que en entrevistas no solo se desprende de la realidad de lo narrado, sino, además, que se proclama en Facebook y en diversos medios desde posturas ideológicas que difícilmente puedan corresponderse con la del narrador de Divórcio.

El otro procedimiento de la ficción tiene que ver con la estructura global de la novela fragmentaria, que itera y vuelve sobre retazos de narraciones, muchos de los cuales han circulado antes del formato libro en otros medios (internet, revistas, plaquetes) del proceso de divorcio empalmados con el diario de la ex mujer de Lísias y las fotografías de su infancia. Aunque aparentemente diferentes, las incrustaciones de esos restos puede pensarse como otro modo que contribuye a desaparecer la autoridad del narrador y, por ende, de la firma Lísias sobre lo narrado. Los restos del diario porque la autora es $X$, cuyo nombre referencial desconocemos, no Lísias y nada indica que lo reproducido en la novela sea efectivamente un diario existente que el sujeto Lísias haya leído y fotocopiado del diario de su mujer en el momento de ruptura de la pareja. De modo que, incluso en este caso, el diario citado se presenta ambiguo para la lectura, porque adquiere para el lector, el estatuto de un elemento desestabilizante, ya que no se puede saber si en efecto los fragmentos fueron extraídos de uno real o directamente son inventados y, por ende, no sabemos quién es el verdadero autor de esos fragmentos, si Lísias el autor o X, cuyo nombre aparece vacío también. Y en ese punto, las firmas se convierten en un elemento de vacío que suspende la lectura en cualquier juicio definitivo. Esto se explica porque, entre el diario y la narración, se dispara un destello de realidad no solo sobre los posibles nombres ocultos que toda la novela menciona, incluso de personajes relacionados con el mundo del periodismo, sino, además, sobre la coincidencia - o no - con la separación de un matrimonio previo y fugaz del propio Lísias. Y esa suspensión de la certeza es aún mayor cuando Lísias, en algunas entrevistas responde lo siguiente: "A ficção e mesmo a obra de arte em geral têm como pressuposto a liberdade de seu espectador. A maneira com que qualquer leitor interpreta o meu livro é de responsabilidade dele próprio. Não tenho nenhum interesse por nada que não seja literatura" (Lísias, 2013b, p. 1).

En esta dirección, las fotografías constituyen otro documento de la novela pero, en este caso, suponen la aparición de la imagen 
desaparecida del autor Lísias en el lenguaje escrito. Es decir, si la fotografía como resto de la realidad del autor Lísias se integra a una novela donde el narrador Lísias esgrime una ficción ideológica del mundo que propone, aparentemente para remarcar su indicialidad verídica y real a lo narrado, lo hace, sin embargo para contribuir aún más a la invención de lo narrado. Me interesa, del grupo de fotografías empalmadas, aquella donde el sujeto Lísias aparece desnudo y con piel en la infancia temprana, ante la mirada del lector que sabe que el sujeto de la novela se dice un cuerpo y una voz muerta y sin piel, herido y despellejado. Esta foto en particular no solo pone en ridículo la voz de autoridad del narrador dejándolo desnudo ante el lector, sino que además, contribuye a remarcar la imposibilidad de la vida sin piel, el artificio en el que se sostiene la trama. Otra vez, la fotografía tiende a divorciar a los Lísias que se componen en la ficción. Pero, además, como el narrador plantea, la mayoría de las fotos familiares suponen un fotógrafo desconocido que capta con su mirada un momento de la vida del narrador o de su familia, pero que ya no aparece en escena o, mejor dicho, que solo ha aparecido en una desaparición de la cual la foto es una huella.

Tanto en el caso del diario como en el de la fotografía, entonces, se trata de expandir un autor sin firma que se disputa la narración de la vida con una atribución autoral ausente, incierta, sospechosa $o$ desconocida que pone en suspenso toda la ficción. Y, en este sentido, el diálogo con el cine de autor que entabla la novela, como el de Lahrs Von Triers, el mismo año en que el director realiza las declaraciones escandalosas en Cannes, no solo vuelve a reponer zonas de autorías que remiten a degradaciones de las figuras sino que extienden la literatura fuera de sí, al ponerla en contacto con autores de otras prácticas artísticas, al tiempo que descompone aún más la imagen de escritor frente a las potencias seductoras del cine tanto para la diarista $X$ como para el mundo contemporáneo. La desvalorización de la autoría y de la imagen de escritor llega, así, a un extremo, revalorizando, paradojalmente, el trabajo ficcional.

Luciene Azevedo en "Ricardo Lísias: versões do autor" (2013) plantea que Lísias aún en 2013, antes de que saliera Dívorcio por Alfaguara, era considerado un autor joven. Hasta O libro dos mandarines, incluso, la crítica había sido reticente, pero ya lo había posicionado como uno de los autores de la nueva ficción brasileña, sobre todo porque "no hablaba de sí mismo, 
lo cual era una marca de la buena ficción". Pero en franco desafío a esa lectura y posición, plantea Azevedo, Lísias produjo una mutación a partir de plaquetes y textos que circularon en diferentes soportes y entre lectores selectos a los cuales el autor enviaba su obra. En ese momento, Lísias define que sus personajes serán él mismo y que se van a llamar Ricardo Lísias. De allí que la exploración con lo biográfico se reacentuó a partir de entonces, pero ya estaba presente en sus ficciones previas a partir de autoplagios y promociones de la obra escrita, así como de marcas biográficas que aparecían fundidas con la ficción. Sin embargo, el verdadero viraje, más allá de "Os tres Marcelos", fue Divórcio, que comenzó a circular fragmentariamente en la revista Piauí en noviembre de 2011, al tiempo que el autor anunciaba su separación en las redes sociales. Desde entonces, la dicción autobiográfica fue un laboratorio para la autofabulación y el viraje fue tal que, asegura Azevedo, a diferencia de las ficciones en primera persona previas, el texto parece todavía más una ficción, ya que tendió a generar una profusión de versiones de textos en diversos formatos antes de decantar en el libro novelístico, pero que repuso con evidencia cómo la figura de autor en el despliegue mutante de la narrativa de Lísias tiende a conformar versiones diferentes y fragmentarias de éste, aunque aparentemente escribe un mismo texto. Es en ese despliegue mutante de la performance narrativa de Lísias en donde también se observa cómo el autor y su firma pasan a formar parte de la verdad de la ficción absoluta en la que devienen, desapareciendo en su hiperaparición e interfiriendo, así, la atribución autoral directa entre firma, narrador y personaje.

\section{Firma y autoría}

En "Sobre las literaturas del presente", Sandra Contreras se pregunta: "No hará falta -mejor dicho, ¿no seguirá haciendo falta- una performance que sea de algún modo una obra (un gesto que es una obra)? ¿No sigue siendo necesaria la firma de artista? ¿O esto es lo que se está transformando justamente: la necesidad de la firma de artista?" (Contreras, 2010, p. 147). De alguna manera, tanto las ficciones autorales de Lísias como las de Chico Buarque aquí trabajadas resitúan y ofrecen respuestas parciales a este problema en la literatura brasileña. Desde perspectivas aparentemente opuestas, ahí donde uno apela a un doble ficcional en el que desaparece y a partir del cual puede trazarse una correspondencia con su hasta entonces dudoso valor como escritor, saltando al reconocimiento de la misma 
manera que el personaje de su ficción; el otro hace de su propia firma y de la identidad onomástica con un narrador protagonista un proceso de desautorización (formal y ético) que complejiza en una zona anfibia de ficción absoluta al autor y al sujeto Ricardo Lísias.

Y si bien las prácticas autorales pueden considerarse disonantes desde las temporalidades de las trayectorias de las firmas que implican, al mismo tiempo, se sostienen en que son parte de un amplio proceso de transformaciones de la ficción brasileña que se opera desde los años '60 (Garramuño, 2009; Dalcastagnè, 2015) y que parecen devenir aún en el presente, ligándolos y diferenciándolos al mismo tiempo con ficciones autorales como las de Clarice Lispector en el caso de Chico Buarque y con las ficciones autorales de Sergio Sant'Anna o de João Gilberto Noll en el caso de Ricardo Lísias.

Sin embargo ambas, entiendo, contrastan y tienden a la comunidad con las prácticas de la literatura marginal de las periferias del presente. Pienso en el caso del "Manifiesto de literatura marginal" (2001) de Ferréz, firma de Reginaldo Ferreira da Silva, donde plantea que luchará por el recuerdo de los autores del ghetto y lanzará sus nombres para que sean eternizados (Sérgio Vaz, Erton Moraes, Jocenir, Paulo Lins, Atrês, Cascao, Ferréz, Edson Veoca, Alessandro Buzo). A diferencia de la ficción que da cuenta de un disvalor de una firma cultural con peso para posicionarse como escritor, o de la afirmación de una misma firma que desautoriza al autor, aquí se trata de hacer visibles los nombres para eternizarlos, para hacerlos oír desde el silencio del margen en que quedan desaparecidos; lejos de tender a la desaparición o a la desautorización, estos nombres, como el de Férrez mismo, pretenden autorizarse y hacerse presentes desde su propia marginación como firmas de autor en la literatura brasileña contemporánea. Es en este sentido, que Heloísa Buarque de Hollanda sostiene que a diferencia de la literatura marginal carioca, los marginales de los saraus "nao sao exactamente contra o 'sistema', como seus antecessores cariocas, mais exigem, com garra, ingêrencia neste sistema" (2009, p. 29). Y si esto da cuenta de dos modos en apariencia contrapuestos de autoría en el presente, también señala hasta qué punto la escritura, sin neutralizar las diferencias, propende un contacto de prácticas provenientes de las antípodas sociales y culturales por medio de un sistema de inversión de los valores puestos en sus gestos autorales. Lo que aparece allí es el poder de la escritura como práctica comunitaria que, aún en el presente, se impone 
inasimilable, incluso, entre y más allá de las diferencias sociales, para suturar, en términos de Daniel Link, el hiato que la separó de la vida.

Pero la pregunta de Contreras también se puede leer en otro sentido que los dos gestos autorales aquí analizados parecen señalar. Se trata de algo que Marcelo Topuzian (2014, p. 21) identifica con precisión al comienzo de su libro Muerte y resurrección del autor (1963-2005): "hay que preguntarse qué es un autor en el presente, cuando el mercado de los bienes culturales parece moverse constitutivamente entre el desarmado del autor en sentido profesional, [...] y su generalización y profundización, por otro, en un remedo mercadotécnico y publicitario del artista de las concepciones estéticas de la cultura". Es decir, lo que estas ficciones preguntan y responden también es qué es ser un autor en un momento en que su propia gestualidad que "garantiza la vida de la obra solo a través de la presencia irreductible de un borde inexpresivo" (Agamben 2006, p. 91), es uno de los elementos centrales no solo de la ficción misma, sino de la trayectoria que esta realiza en un mercado que tiende a refuncionalizarla y volverla utilitaria a su lógica de la ganancia económica.

Si bien el destino y la inscripción de las obras de Buarque y de Lísias no dejan de visibilizar cómo la firma de una obra se convierte en una mercancía que el mercado vende e institucionaliza mediante dispositivos diversos, aprovechando los sistemas de valoración de las artes involucradas (literatura, cine, música) y el 'prestigio' que portan los nombres, todo lo cual impacta en una venta desmedida de las propias novelas aquí analizadas; al mismo tiempo, su compleja atribución autoral somete la escritura a una zona de mutación y complejidad autoral, disciplinar y cultural que genera problemas de clasificación y de valoración unívocos para el mercado cultural. Es decir, la ficción suspende o pone en entredicho aquello que, sin embargo, el mercado no deja de institucionalizar: la firma de autor. Con esto no quiero decir que tales ficciones se sostengan en un sistema de producción fuera del mercado, pero sí que, incluso desde el interior de esos mercados, ellas portan el signo evidente de una inminencia que anticipa el final de su hegemonía sobre la producción artística, una inminencia que, sin embargo, también nos recuerda que no siempre la literatura y los escritores necesitaron del mercado y de las firmas para escribir. Es decir, en tanto que las ficciones de Buarque y de Lísias tienden a desautorizar o deflacionar su atribución autoral, ese logo mercantilizado del autor se desafirma en tanto vacío o resto inasimilable, convencional, artificial e 
inventado, reafirmando la potencia de las prácticas múltiples en que deviene la literatura contemporánea para sobrevivir a cualquier determinación $\mathrm{o}$, por lo menos, generarle una pequeña grieta lanzada a convertirse en un divorcio definitivo.

\section{Referências}

ACADÊMICOS divulgam carta a favor das biografias não autorizadas (2013). Folha de S. Paulo, São Paulo, Caderno Ilustrada, 11 nov. Disponible en: https://goo.gl/oyhvUo. Acceso en: 12 mayo 2016.

AGAMBEN, Giorgio (2006). El autor como gesto. In: AGAMBEN, Giorgio. Profanaciones. Traducción de Flavia Costa y Edgardo Castro. Buenos Aires: Adriana Hidalgo.

AZEVEDO, Luciene (2013). Ricardo Lísias: versões de autor. In: CHIARELLI, Stefania; DEALTRY, Giovanna; VIDAL, Paloma (Org.). O futuro pelo retrovisor: inquietudes da literatura brasileira contemporânea. Rio de Janeiro: Rocco.

BOURRIAUD, Nicolas (2008). Estética relacional. Traducción de Cecilia Beceyro y Sergio Delgado. Buenos Aires: Adriana Hidalgo.

BUARQUE, Chico (2003). Budapeste. Rio de Janeiro: Companhia das Letras.

BUARQUE, Chico (2013). Penso eu. O Globo, Rio de Janeiro, 16 out. On-line. Disponible en: http://oglobo.globo.com/cultura/penso-eu-10376274. Acceso en: 12 mayo 2016.

BUDAPESTE (2009). Direção de Walter Carvalho. Roteiro de Rita Buzzar. São Paulo: Nexus Cinema e Video. (1h53min)

CONTRERAS, Sandra (2010). Sobre las literaturas del presente. In: ALBERTO, Giordano (Comp.). Los límites de la literatura. Rosario: EUNR.

DALCASTAGNÈ, Regina (2015). Representación y resistencia en la literatura brasileña contemporánea. Buenos Aires: Eudeba.

FERRÉZ (2001). Manifiesto de literatura marginal. Traducción de Lucía Tennina. Buenos Aires: Tinta Limón.

GARRAMUÑO, Florencia (2105). Mundos en común. Buenos Aires: FCE.

GARDIES, René (Comp.) (2014). Comprender el cine y las imágenes. Buenos Aires: La Marca. 
JULLIER, Laurent ; LEVERATTO, Jean-Marc (2012). Cinéfilos y cinefilias. Buenos Aires: La Marca.

HAUSER, Arnold (1978). Historia social de la literatura y el arte. Traducción de A. Tovar y F. P Varas-Reyes. Barcelona: Guadarrama.

HOLLANDA, Heloísa Buarque de (2009). Marginais \& marginais. Boletín Kaos, n. 9, São Paulo, p. 13-32, Dic.

LÍSIAS, Ricardo (2013). Divórcio. São Paulo: Alfaguara.

LÍSIAS, Ricardo (2013). Em Divórcio, o drama pessoal é ponto de partida para a ficção. Entrevista a Luciano Trigo. Blog Máquina de Escrever. On-line. Disponible en: https://goo.gl/PNy5Qy. Acceso en: 12 mayo 2016.

MAGDALENO, Renata (2014). O casamento entre a crítica e a ficção. Saga. Revista de Letras, Rosario, n. 1, p. 1-19.

MARTINS, Anna Faedrich (2014). Autoficções. Do conceito teórico à prática na literatura brasileira contemporânea. Tesis (Doutorado em Literatura) - Pontifícia Universidade Católica do Rio Grande do Sul, Porto Alegre.

SAER, Juan José (1991). El concepto de ficción. Punto de vista, Buenos Aires, año XIV, n. 40, p. 35-37, jul.-sept.

SANTOS, Georgiana Coelho (2012). Budapeste: a legitimação do romance no meio literário. Dissertação (Mestrado em Letras) - Universidade Federal da Paraíba, João Pessoa.

TOPUZIAN, Marcelo (2014). Muerte y resurrección del autor (1963-2005). Santa Fe: UNL.

Recebido em fevereiro de 2016.

Aprovado em julho de 2016.

\section{resumo/abstract/resumen}

\section{Assinatura e autoria em Budapeste, de Chico Buarque, e Divórcio, de Ricardo Lísias}

Cristian Molina

Neste artigo, trabalho a relação entre a assinatura e autoria nos romances Budapeste, de Chico Buarque, e Divórcio, de Ricardo Lísias. Explorarei o gesto da autoria como elemento à margem e inexpressivo, que se torna presente pelo uso 
das assinaturas de autor que as duas ficções fazem. Na de Lísias, como jogo de espelhos entre um ghostwriter que se torna reconhecido em um país estrangeiro, e em Chico Buarque, na medida em que a imagem de escritor cresce a partir da publicação do livro. Além disso, analisarei a versão cinematográfica de Walter Carvalho, Budapeste (2009), que redefine o mesmo jogo do romance, mas agora no cinema, abrindo uma área de autoria coletiva sobre a ficção. Em Divórcio, Ricardo Lísias escreve um jogo de correspondência entre a assinatura, o narrador e a personagem, mas a partir de uma desvalorização da imagem do autor que escreve. Essas duas formas permitem-me repensar o que significa ser um autor e ler algumas das condições da ficção brasileira do presente.

Palavras-chave: assinatura, autoria, Chico Buarque, Ricardo Lísias.

\section{Signature and authorship in Budapeste, by Chico Buarque, and Divórcio, by Ricardo Lísias}

\section{Cristian Molina}

In this paper I approach the relationships between signature and authorship in Budapeste, by Chico Buarque and Divórcio, by Ricardo Lísias. It is my interest to linger in the gesture as an inexpresive edge that becomes present in the usage of authorials signatures that both fictions do. One as a mirror game between a ghostwriter that becomes recognized in a foreign country and Chico Buarque, who's impact as a writer grows from the publication of his book. Besides, I stop in how the cinematographic version of Walter Carvalho of 2009, Budapeste, reinstates the same fictional game of a novel, now drag to the cinema and opening a collective authorship zone regarding fiction. The second novel, Divórcio, by Ricardo Lísias, allow us to stop in a coincident game between authorial signature, narrator and character, but starting from a devaluation of the authorial image that that signature writes. These two ways allow me to rethink what it means to be an author and to read some of the conditions of Brazilian fiction - and south American - of the present

Keywords: signature, authorship, Chico Buarque, Ricardo Lísias.

\section{Firma y autoría en Budapeste, de Chico Buarque, y en Divórcio, de Ricardo Lísias}

\section{Cristian Molina}

En este trabajo abordo las relaciones entre firma y autoría en Budapeste, de Chico Buarque y en Dívorcio, de Ricardo Lísias. Me interesa detenerme en el gesto como borde inexpresivo que se vuelve presente en el uso de las firmas autorales que las dos ficciones realizan. Una como juego de espejos entre un ghostwriter que se 
vuelve reconocido en un país extranjero y Chico Buarque, cuyo impacto como escritor crece a partir de la publicación del libro. Además, me detengo en cómo la versión cinematográfica de Walter Carvalho de 2009, Budapeste, repone el mismo juego ficcional de la novela, ahora arrastrado al cine y abriendo una zona de autoría colectiva respecto de la ficción. La segunda novela, Dívorcio, de Ricardo Lísias, permite detenernos en un juego coincidente entre firma autoral, narrador y personaje, pero a partir de una devaluación de la imagen autoral que esa firma escribe. Estas dos formas me permiten repensar qué significa ser un autor y leer algunas de las condiciones de la ficción brasileña - y conosureña - del presente.

Palabras clave: firma, autoría, Chico Buarque, Ricardo Lísias. 